\title{
SIDEROPHORE MEDIATED METAL UPTAKE BY PSEUDOMONAS FLUORESCENS AND ITS COMPARISON TO IRON (III) CHELATION
}

\author{
Aditi Bhattacharya \\ HOD Microbiology, Dr. Rafiq Zakaria Campus, Maulana Azad College, Aurangabad (M.S), India \\ Accepted 20 December 2010
}

\begin{abstract}
Siderophores are iron chelating substances that are also known to bind metals such as Molybdenum and Lead. The pigment produced by $P$. fluorescens is a siderophore whose ability to bind to different metal ions was investigated in this study. Pigment production was increased in the presence of Sodium, Potassium, Lead, Molybdenum and Cadmium. Siderophores were detected using CAS assay and catechol siderophores by Arnow assay. Peak changes and changes in extinction coefficient values are indicators of complex formation. Maximum difference was observed in siderophore free Iron and Iron-siderophore complexes. Some changes were also noted for siderophore- metal complexes for all metals included in this study. Thus siderophore of $P$. fluorescens shows a tendency to form complexes with almost all metals tested.
\end{abstract}

Key words: pigment, CAS assay, metal ions, complex formation, peak changes, molar extinction coefficient.

\section{INTRODUCTION}

Iron, one of the most essential microelements for virtually all living cells, is usually abundant in the environment, particularly in soils and natural aquifers. However, its bioavailability is relatively low, which is connected with a dramatically decreased solubility of ferric species under physiological $\mathrm{pH}$ values owing to their complete hydrolysis. This has resulted in the development of special biologically regulated mechanisms of $\mathrm{Fe}(\mathrm{III})$ solubilization, e.g., involving specific natural low-molecularweight chelating agents (siderophores) which transport iron(III) to the cell surface in the form of a complex, with further $\mathrm{Fe}(\mathrm{III})$ release from the latter in the course of its reductive assimilation (Kamnev et al., 2000). Many microorganisms possess high affinity iron uptake system mediated by the action of low molecular weight iron chellators termed as siderophores (Lankford, 1973; Neilands, 1981). The fluorescent Pseudomonas are characterized by yellow green pigments that fluoresce under UV irradiation and function as siderophores termed pyoverdins, and pseudobactins (Meyer and Abdallah, 1978). The following study investigates the ability of siderophores to chelate other metal ions as has been reported for iron.

\section{MATERIALS AND METHODS}

Ioslation of Pseudomonas spp was done on Kings A and B medium (Deshmukh, 1997) from rhizopheric soil as well as phyllospheres of ornamental plants. Colonies with characteristic pigments were tested biochemically and identified using the Bergey's manual of systematic Bacteriology. Pigment production was tested in SM medium (Meyer and Abdallah, 1978), Barabhaiyya and Rao medium (BR) (Barabhaiyya and Rao, 1985), Pseudomonas F broth, Cetrimide broth, Nutrient broth, LB medium (Deshmukh, 1997), Low iron Fiss minimal media (Vellore, 2001) and M63 succinate minimal broth (Khare et al.,1997) respectively.

Metal tolerance and siderophore production.

The ability to tolerate metals was determined by incorporating 16 different metal salts individually at $200 \mu \mathrm{g} / \mathrm{ml}$ (Sayyed et al., 2005) in SM medium. Absorbance at $600 \mathrm{~nm}$ along with total cell proteins (Lowry et al., 1951) were determined and intensity of pigment formation was noted on a visual scale of 1 to 4 after $48 \mathrm{~h}$ of growth at $30{ }^{\circ} \mathrm{C}$.

*Corresponding author's email: aditivb@indiatimes.com. 


\section{CAS assay}

CAS assay (Schwyn and Neilands, 1987) was carried out for detection of siderophores. Pseudomonas fluorescens was grown in Fiss's iron deficient medium (at iron concentration of $135 \mu \mathrm{g} / \mathrm{ml})$ as well as in iron modified Fiss minimal media (5.56 mg/l; Vellore, 2001). CAS agar plates were used for detection of siderophores. Culture supernatant $(20 \mu \mathrm{l})$ was applied to wells of CAS agar plates and incubated at $30^{\circ} \mathrm{C}$ for 5 days. Siderophoreproducing $\left(\mathrm{Sid}^{+}\right)$culture supernatant develops an orange halo.

\section{Arnow assay}

The presence of catechol-phenolic type siderophores was detected using Arnow assay in cell free supernatants grown in low as well as high iron Fiss's minimal media (Arnow, 1937).

\section{Extraction and TLC}

Pseudomonas fluorescens was grown for 3 days in BR medium and Nutrient broth which were suitable for intense pigment production. The culture free broth was extracted with equal volumes of isopropanol and chloroform (Tobie, 1945) and the resultant solvent fractions was allowed to evaporate under refrigeration. The extract was redissolved in $5 \mathrm{ml}$ of distilled water and used as a crude siderophore preparation for TLC as well as for metal complexation studies. TLC was done using a tertiary mixture of $n$ butanol, acetic acid and distilled deionised $\mathrm{H}_{2} \mathrm{O}$ in a ratio of 3:1:1. (Johnson, 1977). Plates were dried and observed under UV light for detection of fluorescence.

\section{Detection and estimation of siderophores}

Culture supernatants from King's B medium was used for recording absorbance over a wavelength of 200-700nm. Pseudomonas fluorescens was grown in Fiss's iron deficient medium for $48 \mathrm{~h}$.Culture supernatants were used for determining the amount of siderophore in culture medium at $\lambda_{\max }$ of $400 \mathrm{~nm}$ (Rachid and Bensoltane, 2005) and calculated as follows:

Concentration $=$ O.D/ $\varepsilon$ x1 (where molar coefficient $\varepsilon=2000$ moles/litre) (Jayaraman, 1996).

\section{Metal complexation studies}

Metal-siderophore complexation was allowed at metal concentration of $50 \mu \mathrm{g} / \mathrm{ml}$ for 3 h. at room temperature. A spectral scan (200 to $700 \mathrm{~nm}$ ) was conducted to determine the $\lambda_{\max }$ of siderophore free metal and metal - siderophore complexes. Sampling was carried out in triplicate and average values have been reported.
The molar extinction coefficients and ' $\varepsilon$ ' (\% moles/litre) were calculated (Jayaraman, 1996) as follows:

$\mathrm{A}$ or $\mathrm{E}=\log 100 / \mathrm{T}=2-\log \mathrm{T}$ (where $\mathrm{A}$ is the absorbance and $\mathrm{E}$, the extinction)

$\varepsilon=\mathrm{E} / \mathrm{C} \times 1$ (where $\mathrm{C}$ or concentration $=0.05$

$\mathrm{g} /$ litre and 1 or length of light path $=1 \mathrm{~cm}$ )

\section{RESULTS AND DISCUSSION}

The isolate obtained on King's B medium was biochemically confirmed as P. fluorescens using Bergey's manual of systematic Bacteriology (Table 1). Typical yellowish blue UV fluorescence was detected on TLC plates. When such spots were eluted and redissolved in isopropanol or chloroform, the $\lambda_{\max }$ was found to be $363 \mathrm{~nm}$ (Fig. 1), characteristic of pyoverdins (360 to $420 \mathrm{~nm}$ ). However the elute could not be used in subsequent metal chelation studies as the quantity of siderophores containing elute was too little for metal chelation. Metal chelation studies were thus carried out after solvent extraction of the growth medium. The solvent phase was allowed to evaporate and the residue was resuspended in deionised water. Since the pigment is itself a siderophore and an iron chelator (Meyer, 2000) therefore fluorescence and peak at $363 \mathrm{~nm}$ confirms the production of siderophores. The siderophore color could mainly be attributed to the $402 \mathrm{~nm}$ peak (Bultreys et al., 2001).

Table 1. Biochemical characteristics of P.fluorescens.

\begin{tabular}{|lc|}
\hline Biochemical tests & Results \\
\hline Catalase & + \\
Oxidase & - \\
Lecithinase & + \\
Gelatin hydrolysis & + \\
Starch hydrolysis & - \\
Argenine dihydrolase & + \\
Urease & + \\
Nitrate reductase & - \\
Growth on King's & $\mathrm{B}$ \\
medium & + \\
Cetrimide agar & + \\
Growth at $41^{0} \mathrm{C}$ & - \\
Growth at $4{ }^{0} \mathrm{C}$ & + \\
Gram's nature & Gram negative \\
UV Fluorescence & + \\
\hline
\end{tabular}

The peaks for partially purified siderophore was in the range of 290 to 300 (Table 4 computed from Figs. 2A to 2O). Since the pigment was extracted from the growth medium, 


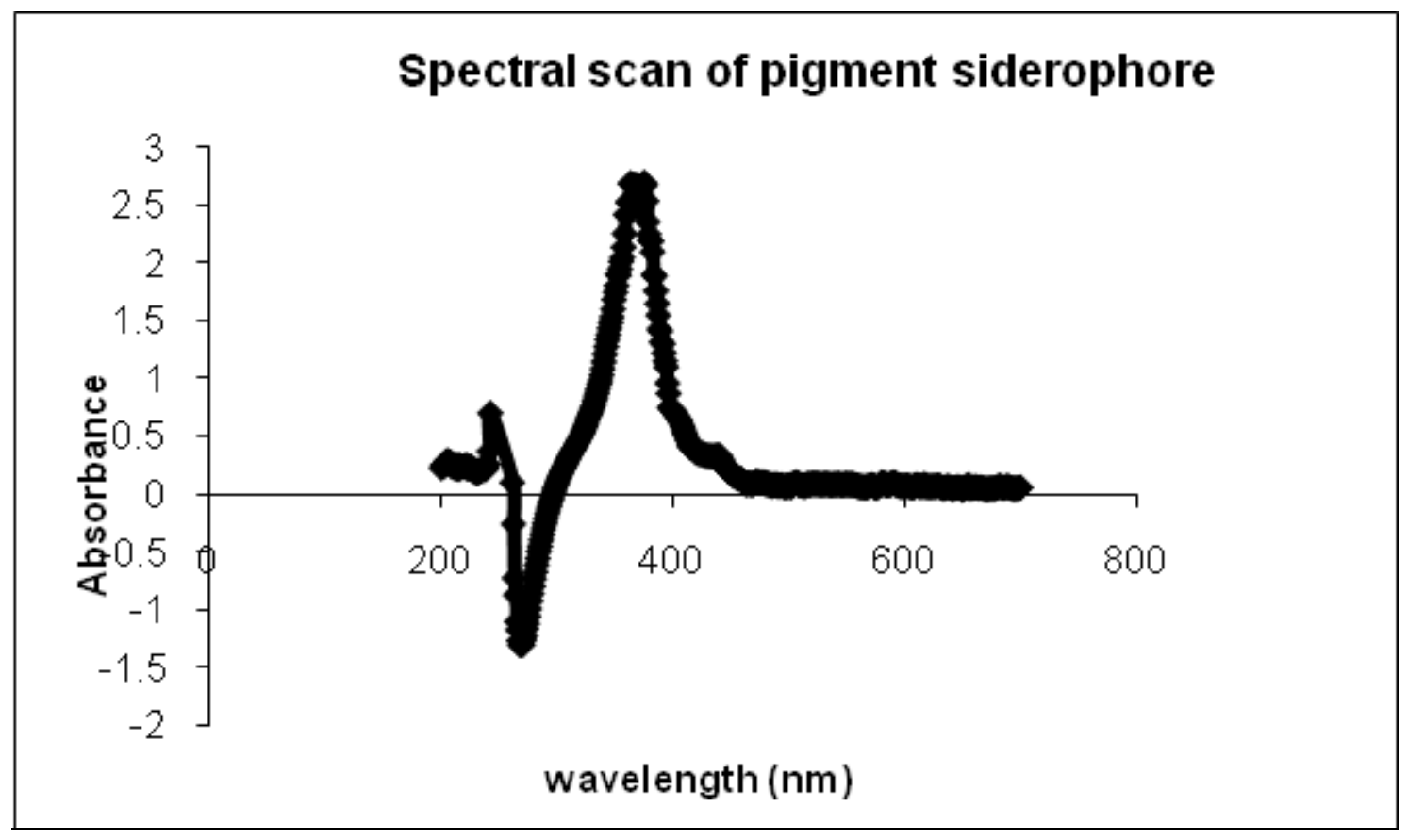

Figure 1. Spectral scan of the eluted siderophore-pigment after TLC.

Table 2. Differences in $\lambda$ max and molar extinction coefficient with reference to siderophore free and metal incorporated siderophore complexes.

\begin{tabular}{|c|c|c|c|c|}
\hline \multirow[t]{2}{*}{ Metal added } & \multicolumn{2}{|c|}{ Siderophore free -metal } & \multicolumn{2}{|c|}{ Siderophore-metal complexes } \\
\hline & $\lambda \max$ & $\varepsilon(\%$ moles/litre $)$ & $\lambda \max$ & $\varepsilon(\%$ moles $/$ litre $)$ \\
\hline Sodium & 293 & 37.7 & 290 & 34.9 \\
\hline Potassium & 292 & 37.9 & 286 & 35.4 \\
\hline Calcium & 292 & 39.6 & 305 & 31.9 \\
\hline Iron & 295 & 31.9 & 300 & 43.4 \\
\hline Zinc & 294 & 37.1 & 287 & 34.4 \\
\hline Lead & 291 & 40.8 & 299 & 29.3 \\
\hline Silver & 300 & 31.9 & 300 & 31.9 \\
\hline Mercury & 297 & 33.8 & 302 & 31.2 \\
\hline Cadmium & 291 & 39.7 & 299 & 31.9 \\
\hline Chromium & 292 & 39.6 & 302 & 31.9 \\
\hline Nickel & 291 & 41.2 & 299 & 29.3 \\
\hline Molybdenum & 288 & 41.9 & 297 & 29.3 \\
\hline Copper & 295 & 36.6 & 300 & 31.9 \\
\hline Magnesium & 290 & 40.9 & 299 & 29.4 \\
\hline Manganese & 292 & 41.0 & 301 & 31.9 \\
\hline None & 293 & 37.7 & 290 & 33.9 \\
\hline
\end{tabular}

interference in absorption with respect to unused media constituents, degraded products and metabolites produced cannot be ruled out.

Several researchers reported the presence of siderophore, a polar substance with bands of absorption at different wavelengths such as 260 $\mathrm{nm}$ and $402 \mathrm{~nm}, 448 \mathrm{~nm}$, absorbance maxima of
365 and $410 \mathrm{~nm}$ for pyoverdins pss and its ferric chelate, respectively (Cody and Gross, 1987), $350-600 \mathrm{~nm}$ in absence and presence of iron (Parker et al., 2004). The reports indicate a shift on the longer wavelength side after iron chelation and the same has also been observed in this study.(Fig. 2B). Peak shift on the longer wavelength side has also been observed with 
respect to $\mathrm{Ca}$ (Fig. 2D), $\mathrm{Pb}$ (Fig. 2F), $\mathrm{Hg}$ (Fig. 2H), Cd (Fig. 2C), Cr (Fig. 2A), Ni (Fig. 2K), Mo (Fig. 2J), Cu (Fig. 2E, Mg (Fig. 2I), Mn (Fig. 2G; Table 2).

Excellent growth and pigment production was detected in BR medium. BR medium has succinate which favors pigment production and is used as a carbon source by Pseudomonas. It was reported by Meyer and Abdallah (1978) that pyoverdin excretion in $P$. fluorescens increased in standard succinate medium under iron depleted conditions. Barbhaiya and Rao (1985) also reported that succinate and ammonium sulphate were the best sources of carbon and nitrogen for pyoverdin production. Chodat and Gouda (1961) have attributed an important role in pyoverdin synthesis to the nature of the carbon source for growth and succinate is classified as a chromogenic substrate increasing sidorophore yields. Total cell proteins decreased considerably in presence of Silver, Chromium and Copper as heavy metals exert oligodynamic action. Many metallic elements have been observed to inhibit the growth of bacteria and to inactivate enzymes (Charles et al., 1948). Metal free media (control) showed higher total proteins and Manganese, Magnesium or Potassium did not inhibit growth. $\mathrm{Mn}, \mathrm{Mg}$ or $\mathrm{K}$ are physiological ions and hence did not inhibit the growth of the organism. It was reported by Abd Rahman et al. (2004), that metal ions such as $\mathrm{K}^{+}$, $\mathrm{Mg}^{2+}$ and $\mathrm{Ca}^{2+}$ maximized enzyme production in Pseudomonas aeruginosa.

Intensity of the pigment was highest in presence of Sodium, Potassium, lead, Molybdenum and Cadmium (Table 3). Sayyed et al. (2005) reported that lead triggered growth as well as siderophore synthesis. Siderophores have been shown to have a high affinity for a variety of metal ions concerned such as $\mathrm{Cd}, \mathrm{Cu}, \mathrm{Pb}, \mathrm{Zn}$, Al etc (Chamongkolpradit et al., 2008). Thus their chelation probably reduced their toxicity and hence allowed pigment production.

Siderophore indicating orange halos were observed after 5 days of incubation on CAS medium. Pinkish-red colour was noted in Fiss's low iron medium in presence of excess of $\mathrm{NaOH}$ (catechol siderophores) but could not be detected in modified Fiss's medium (high iron). Highest concentration of siderophore was detected in metal free low iron Fiss minimal media. The production of siderophores depends on iron concentration in the medium and was thus in agreement with the findings of Kloepper et al.
(1980). Low or no iron stimulated the production of siderophores (Tables $2 \& 3$ ).

CAS assay is the universal assay for detection of siderophores. The principle of this assay is based on a color change of CAS from blue to orange resulting from siderophoral removal of $\mathrm{Fe}$ from the chrome azurol dye (Guan et al., 2001). Arnow assay was also done to detect catechol - phenolic siderophores. Catechol combines with nitrous acid giving a yellow colour, which becomes intense orange red in presence of excess $\mathrm{NaOH}$.

Table 3. Growth and pigment production in SM medium.

\begin{tabular}{|llll|}
\hline Metal & $\mathbf{A}_{\mathbf{6 0 0}}$ & $\begin{array}{l}\text { Total } \\
\text { proteins } \\
(\boldsymbol{\mu g} / \mathbf{m l})\end{array}$ & $\begin{array}{l}\text { Intensity } \\
\text { of } \\
\text { pigment }\end{array}$ \\
\hline Sodium & 1.423 & 14.75 & ++++ \\
Potassium & 2.106 & 22.95 & ++++ \\
Calcium & 1.317 & 19.67 & +++ \\
Iron & 1.332 & 13.11 & - \\
Zinc & 1.076 & 14.75 & + \\
Lead & 1.673 & 16.39 & ++++ \\
Silver & 0.648 & 6.55 & - \\
Mercury & 0.929 & 11.47 & - \\
Cadmium & 1.248 & 11.47 & ++++ \\
Chromium & 0.462 & 6.55 & - \\
Nickel & 0.545 & 11.47 & - \\
Molybdenum & 1.251 & 19.67 & ++++ \\
Copper & 0.662 & 8.19 & + \\
Magnesium & 1.553 & 22.95 & +++ \\
Manganese & 2.708 & 27.86 & +++ \\
None & 2.674 & 32.78 & ++++ \\
\hline
\end{tabular}

Table 4. Estimation of siderophore produced in Fiss's minimal medium.

\begin{tabular}{|llc|}
\hline Metal added & $\mathbf{A}_{\mathbf{4 0 0}}$ & Siderophores $(\boldsymbol{\mu g} / \mathbf{m l})$ \\
\hline Sodium & 1.264 & 0.0632 \\
Potassium & 1.583 & 0.0791 \\
Calcium & 1.397 & 0.0698 \\
Iron & 0.629 & 0.0314 \\
Zinc & 1.273 & 0.0636 \\
Lead & 1.218 & 0.0609 \\
Silver & 1.183 & 0.0591 \\
Mercury & 1.166 & 0.0583 \\
Cadmium & 1.232 & 0.0500 \\
Chromium & 1.207 & 0.0603 \\
Nickel & 1.174 & 0.0587 \\
Molybdenum & 1.232 & 0.0616 \\
Copper & 1.182 & 0.0591 \\
Magnesium & 1.410 & 0.0705 \\
Manganese & 1.252 & 0.0626 \\
None & 1.716 & 0.0858 \\
\hline
\end{tabular}


2A. Scan of chromium and SiderophoreChromium complex

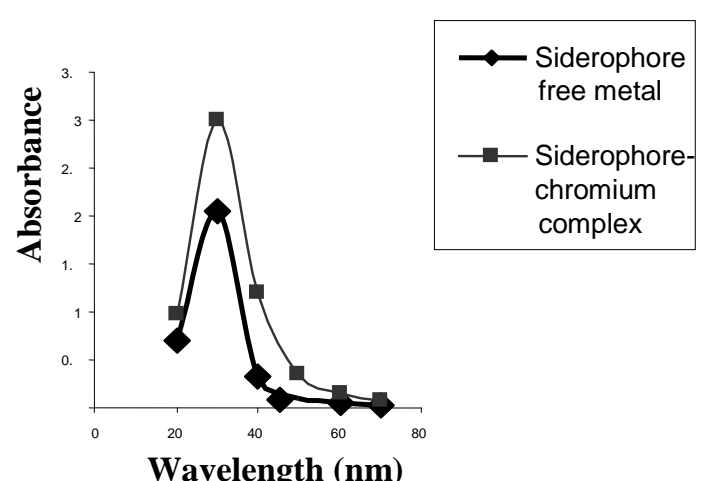

2C. Scan with Cadmium and CadmiumSiderohore complex

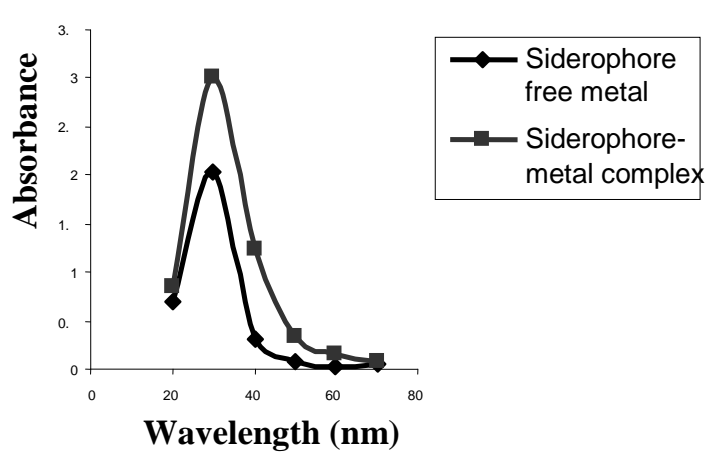

2B. Scan of Iron and Iron- Siderophore complex

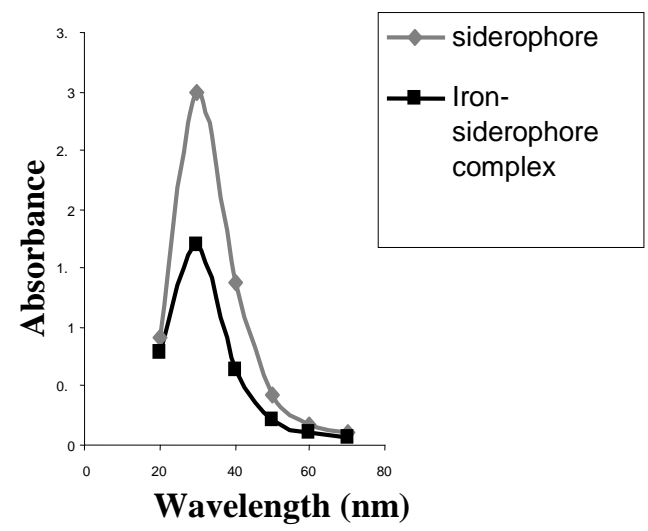

2D. Scan with Calcium and CalciumSiderophore complex

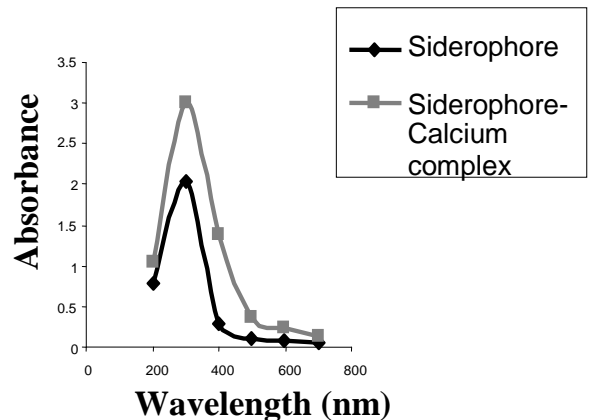

2F. Scan with lead and lead-siderophore complex copper complex

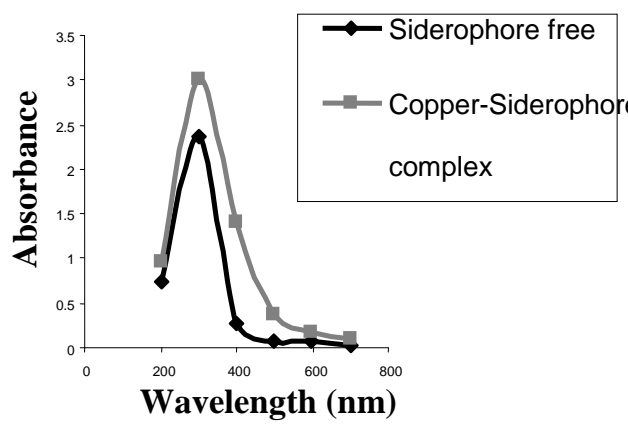


2G. Scan of Manganese and siderophore-Mn complex manganese complex

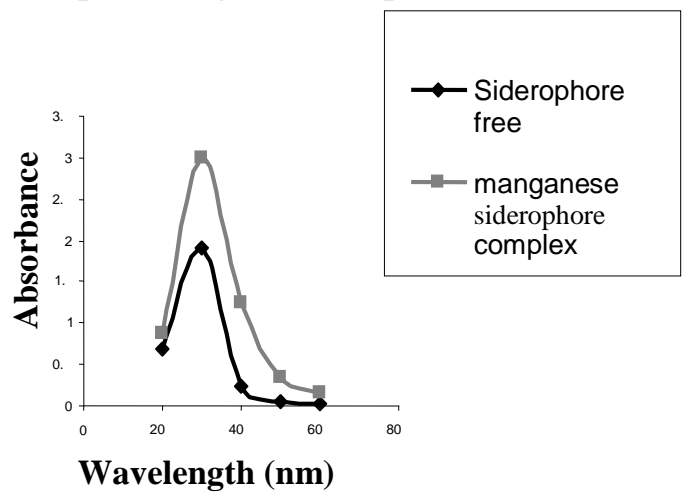

2I. Scan of Magnesium and SiderophoreMagnesium complex

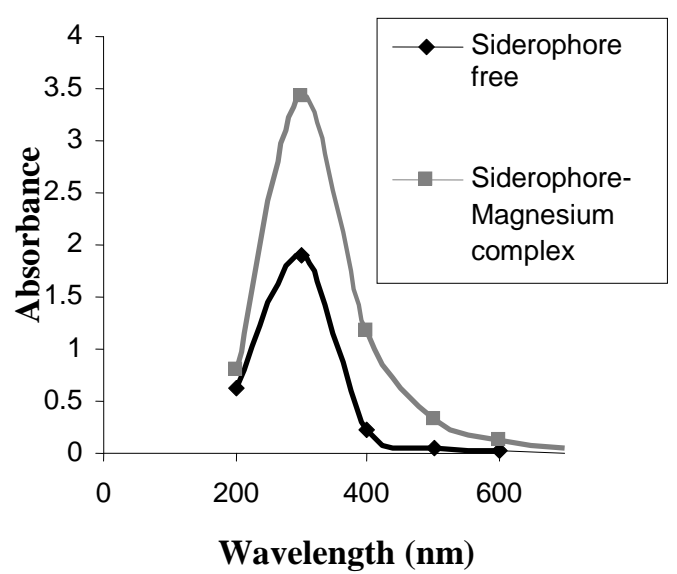

2K. Scan of Nickel and Nickel- siderophore complex

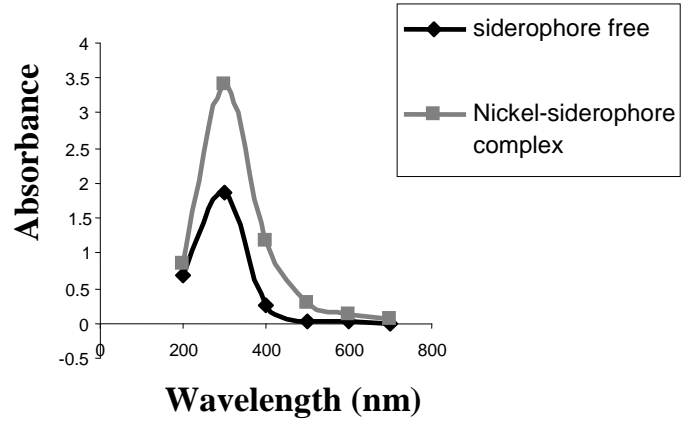

2H. Scan of Mercury and Mercurysiderophore complex

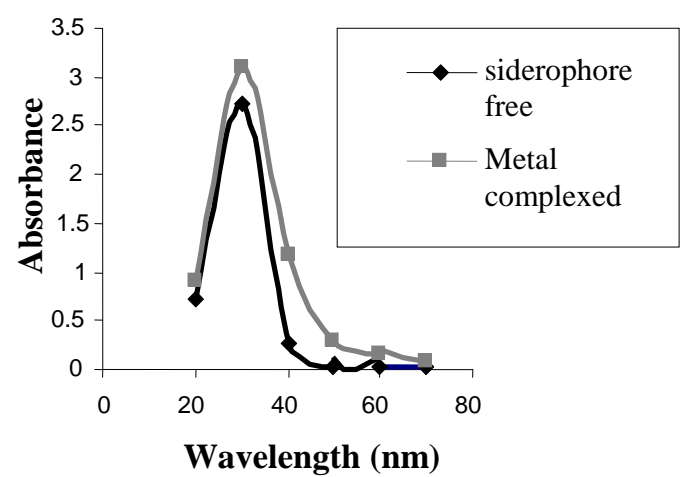

J. Scan of Molybdenum and siderophoresMo complex

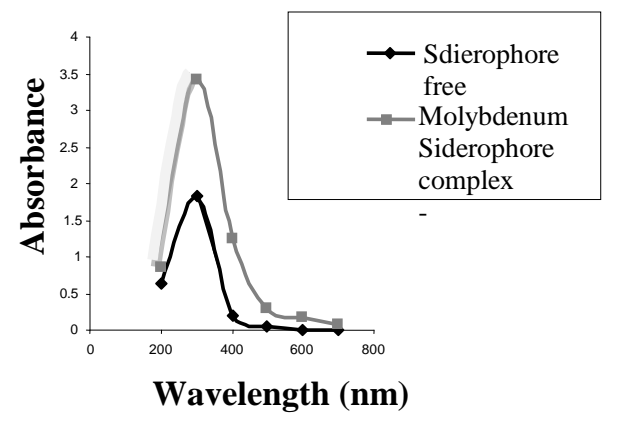

2L. Scan of Potassium and Siderophore Potassium complex

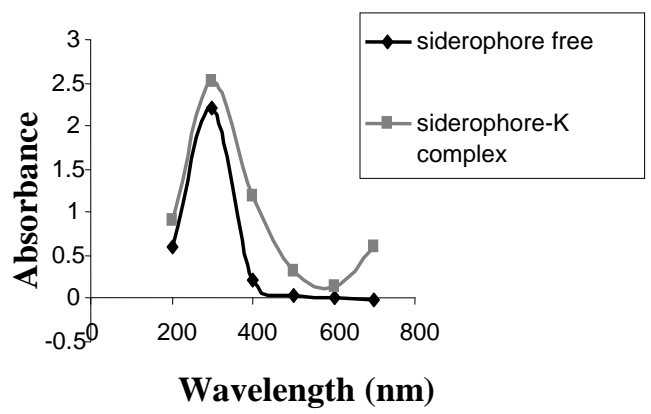


2M. Scan of Silver and Silver- Siderophore complex

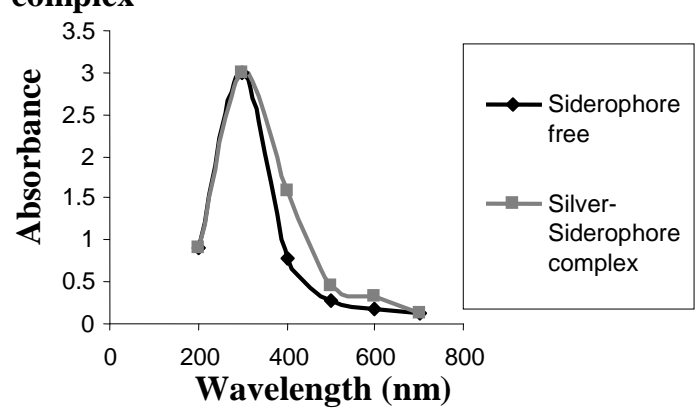

20. Scan of Zinc and SiderophoreZinc complex

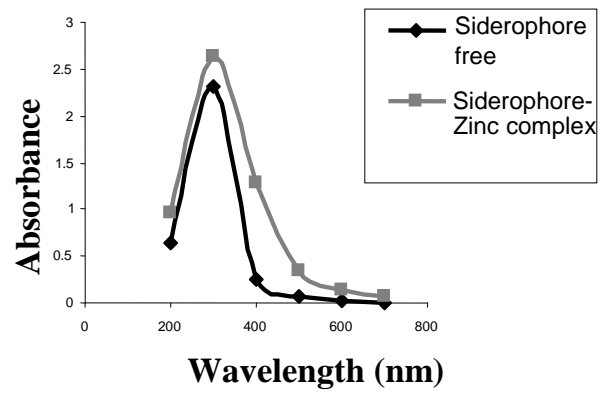

2N. Scan of Sodium and SiderophoreSodium complex

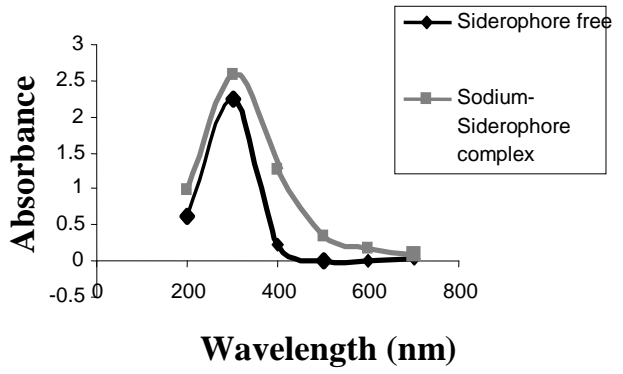

Figure 2. A - O. Spectral scan with respective metals in the presence and absence of the siderophore.

Presence of Potassium, Magnesium and Calcium had little inhibitory effect on siderophore production compared to controls (Table 4). It was reported by Nies (1999) that some of the metal cations play an important role as trace elements in biochemical reactions. Therefore pigment production and growth was not affected in presence of these metal ions.

Widening of FWHM on the longer wavelength side has been noted for most metals except iron (Fig. 2B). Fall in graph also indicates the ability of the siderophore to show absorption over longer wavelengths i.e. 500-700 nm (Table 2 and Figs. 2A to 2O). Full width at half maximum (FWHM) is a criterion that indicates complex formation (Griem, 1968). Widening of FWHM on the longer wavelength side indicates some sort of complex formation with the siderophore. It also indicates that the atomic, ionic and molecular densities have increased. Density, a measure of mass (Griem, 1968) had increased because of possible incorporation of the metal in the siderophore. Such an increase in FWHM has also been reported with respect to Iron citrate-Lotibactin, a siderophore synthesized by Mesorhizobium loti (Morton et al.., 2007). The fall is graph has been found to be exceptionally sharp in siderophore free metal solution.(Figs. 2A to 2O). Thus siderophore allowed the measurement of absorbance, which was not possible in the absence of the siderophore.

Molar extinction coefficients have been determined in partially purified extracts of siderophores after chloroform extraction (Demange et al., 1988; Meyer and Abdallah, 1978). The extinction coefficient for Silver and Silver - siderophore complex remained unchanged indicating no complex formation as silver is a noble metal (Table 2 \& Fig. 2M). Complex formation also changes the transmission coefficient of light. The extinction coefficient was reduced in presence of siderophore for most of metals except iron.

The role of alkalophilic bacterial siderophores in removal of iron, gallium and aluminium from culture media has been reported by Gascoyne et al. (1991). Chamongkolpradit et al. (2008) had reported that siderophores have 
high affinity for $\mathrm{Cd}, \mathrm{Cu}, \mathrm{Pb}, \mathrm{Zn}, \mathrm{Al}$. It was reported by several researchers (Khare et al., 1997; Sayyed et al., 2005; Rachid and Bensoltane, 2005) that siderophores are able to bind with metals such as $\mathrm{Pb}$ and Mo along with Fe. Parker et al. (2004) reported the scavenging of Manganese by pyoverdins.

It can be deduced that siderophore production is reduced at higher concentrations of iron (Table 3) and fluorescent siderophores are produced in the presence of some metal ions. It was also observed that it forms transient complexes with these metal ions as concluded from changes in $\lambda$ max, FWHM and extinction coefficients.

\section{ACKNOWLEDGEMENTS}

The author is thankful to the Director, BCUD, Dr. Babasaheb Ambedkar Marathwada University for providing the grant, the Principal, Maulana Azad College for his encouragement and support and Dr. Smita Tulapurkar for help with the analysis of results.

\section{REFERENCES}

Arnow, L.E. (1937). Colorimetric determination of the components of 3,4dihydroxyphenylalanine tyrosine mixtures, Journal of Biological Chemistry 118: 531-537.

Barbhaiya, H.B and Rao, K.K. (1985). Production of pyoverdin, the fluorescent pigments of Pseudomonas aeruginosa PAO1, FEMS Microbiology letters 27:233-235.

Bultreys, A., Gheysen, I., Maraite, H. and Hoffmann, E. (2001). Characterization of Fluorescent and Nonfluorescent Peptide Siderophores Produced by Pseudomonas syringae Strains and Their Potential Use in Strain Identification. Appl Environ Microbiol. 67(4): 1718-1727.

Chamongkolpradit, W., Budzikiewicz, H., Chanthai, S., and Ruangviriyachai, C. (2008). Immobilisation and characterization of pyoverdins onto modified Micelle-templated silica (MTS) surface as chelating agent. KKU Research journal 3(2):182-196.

Charles, F., Mckhann,M.D, Harve,J, Carlson,P.H and Harriet,D.B.S. (1948).
Oligodynamic action of metallic elements and of metal alloys on certain bacteria and viruses. Pediatrics 2(3):272-289.

Chodat, F. and Gouda, S. (1961). Contribution al étude du pigment de Pseudomonas fluorescens Migula. Pathologia et microbilogia.24:840-847.

Cody, Y.S. and Gross, D.S. (1987). Characterization of PyoverdinpS5, the Fluorescent Siderophore Produced by Pseudomonas syringae pv. Syringaet. Appl. and Environ. Microbiol. 53(5): 928-934.

Demange, P., Batman, A., Dell, A. and Abdullah, A. (1988). Structure of azotobactin D, a siderophore of Azotobacter vinelandii strain D (CCM 289). Biochemistry 27: 2745-2752.

Deshmukh, A.M. (1997). Hand book of media stains and reagents in microbiology 1-255.

Gascoyne, D.J., Connor, J.A., and Bull, A.T. (1991).Capacity of siderophore - producing alkalophilic bacteria to accumulate iron, gallium and aluminum. Environmental Biotechnology 36 (1): $136-141$.

Griem, H.R. (1964). Plasma spectroscopy, McGraw Hills Publications. N.Y.

Griem,H.R. (1968). Semiempirical Formulas for the Electron-Impact Widths and Shifts of Isolated Ion Lines in Plasmas. Physics Review. 165:258.

Guan, L.L., Kanoh, K. and Kamino, K. (2001). Effect of Exogenous Siderophores on Iron Uptake Activity of Marine Bacteria under IronLimited Conditions. Applied and Environmental Microbiol 67 (4): 1710-1717.

Jayaraman, J. (1996). Laboratory manual in Biochemistry. New age international publishers. Pp:3.

Johnson, J. (1977). Utilization of benzylpenicillin as carbon, nitrogen and energy source by a Pseudomonas fluorescens strain. Archives of Microbiology 115 (3): 271-275

Kamnev, A.A., Kuzmann, E., Perfiliev, Y.D, Vértes, A., Ristic', D., Popovic', S. and Musi, S. (2000). Composite ferric oxyhydroxide containing phases formed in neutral aqueous solutions of tryptophan and indole-3-acetic acid Journal of Radioanalytical and Nuclear Chemistry Vol. 246 (1 ):123.129. 
Khare, S., Ganguli, A. and Tripathi, A. K. (1997). Responses of Pseudomonas aeruginosa to chromium stress. European Journal of soil biology 33(3):153-158.

Kloepper, J.W., Leong, J., Teintze, M. and Schroth, M. N. (1980). Enhanced plant growth by siderophores produced by plant growth promoting rhizobacteria. Nature 286: 885 - 886 .

Lankford, E. (1973). Bacterial assimilation of iron. CRC Critical Reviews in Microbiology 2: 273-3 11 .

Lowry, O.H., Rosebrough, N.J., Farr, A.L. and Randall, R.J. (1951). Protein measurement with the Folin phenol reagent. Journal of Biological chemistry 193:265-275.

Meyer, J.M. (2000). Pyoverdines: pigments, siderophores and potential taxonomic markers of fluorescent Pseudomonas species. Arch. of Microbiol. 174(3): 135-142.

Meyer, J.M. and Abdallah, M.A. (1978).The fluorescent pigment of Pseudomonas fluorescens: Biosynthesis, purification and physicochemical properties. Journal of General Microbiology 107:319- 328.

Morton, J., Marsh, K., Frawley, M. and Castignetti, D. (2007). The Response of a Siderophore-Degrading Bacterium (Mesorhizobium loti) to Iron-Deprivation: Evidence of Siderophore and Iron-Repressible Protein Synthesis. Advances in Biological Research 1 (3-4): 122-129, 2007.

Neilands, J.B. (1981). Development of Iron chelators for clinical Use, In: Martell, A.E., Anderson. W.J. and Badman, D.G.North (Eds). Elsevier 13(3). Holland, Amsterdam

Nies, D.H. (1999). Microbial Heavy-metal Resistance. Appl Microbiol Biotechnol. 51:730750 .
Parker,D.L, Sposito,G, Tebo,B.M. (2004). Manganese (III) binding to a pyoverdine siderophores produced by a manganese(II)oxidizing bacterium. Geochimica et Cosmochimica Acta 68: 4809-4820.

Rachid, D. and Bensoltane, A. (2005). Effect of iron and growth inhibitors on siderophores production by Pseudomonas fluorescens. African Journal of Biotechnology 4(7): 697-702.

Rahman, R.N., Geok, L.P, Basri, M. and Salleh, A.B. (2005). An organic solvent-tolerant protease from Pseudomonas aeruginosa strain $\mathrm{K}$ : Nutritional factors affecting protease production. Enzyme and Microbial Technology 36 (5-6): 749-757.

Sayyed, R., Badgujar, M.D., Sonawane, H.M., Mhaske, M.M. and Chincholkar, S.B. (2005). Production of microbial iron chellators (siderophores) by fluorescent Pseudomonads. Indian Journal of Biotechnol. 4:484-490.

Schwyn, B. and Neilands, J.B. (1987). Universal chemical assay for the detection and determination of siderophores. Anal. Biochem. 160:47-56.

Tobie, W.C. (1945). A proposed biochemical basis for the genus Pseudomonas. Journal of Bacteriology 49:459.

Vellore, J. (2001). Iron acquisition in Rhodococcus erythropolis strain IGTS8: Isolation of a non siderophore producing mutant. M.S. Thesis, East Tennesse State University, Jhonson city,TN. 